\title{
Household Livelihood Strategies and Food Security in Angolela Tera District, Ethiopia
}

\author{
Seyfe Fikre \\ Correspondence: Seyfe Fikre, College of Business and Economics, Department of Economics, Bonga University, \\ P.O.Box: 334, Bonga, Ethiopia. E-mail: seyfefikre2008@gmail.com
}

Received: August 20, 2020

doi:10.11114/bms.v6i4.4977
Accepted: September 9, 2020

Online Published: December 7, 2020

URL: https://doi.org/10.11114/bms.v6i4.4977

\begin{abstract}
Worrying about reduction of food insecurity directly or indirectly linked with the livelihood strategy. Food security of the household is a reply of available livelihood strategies. The aim of the study was to examine rural livelihood strategies and its effect on food security. This study examined the effect of household livelihood on food security in Angolela and Tera District by taking randomly selected sample of 256 household and multi-nominal probit regression was used. The household food security was measured by Household Food Insecurity Access Scale (HFIAS). The average HFIAS score was 5.5; lower score was recorded in farming livelihood activities and higher score was recorded in non-farm activities. Finding shows that relatively those respondents who engaged in farming activities were more food secure than those confined to non-farm activities and mixed activities. On the other hand, those household confined only non-farm livelihood were more food insecure. This call for policies and strategies provide the incentive/intervention for the household who are using non-farm activities alone in ensuring their food security in rural area. Government policies need to designed and implemented comprehensive strategies in order to keep non-farm household food security.
\end{abstract}

Keywords: household livelihood strategies, food security, multi-nominal probit regression, HFIAS, rural area

\section{Introduction}

Household Livelihood strategy denotes the range and combination of activities and choices that people make and undertake ways of combining and using assets in order to achieve their livelihood goals (DFID, 1999). According to sustainable livelihood approach constructed in (DFID, 1999) stream of activities will lead to stream of benefit. Household food security is one of the outcomes of livelihood activity. Sustainable livelihood framework provides the way to link household livelihood activity and food security. its eclectic tendency to appraise the resource base of rural households, the way they combine their assets and pursue certain livelihood activities to achieve cherished livelihood outcomes (food security in this study).

Recent empirical evidence suggested that after a prolonged decline, world food insecurity appears to be on the rise again. The estimated number of undernourished people increased to 850 million in 2019, up from 815 million in 2016 (FAO, 2019). According to Rural Poverty Report (2011), much of the recent increase in food insecurity can be traced to the greater number of rural society. The major food insecure populations in the world are smallholder farmer (FAO, 2019). Globally in 2018 around $9.3 \%$ are severely food insecure, out of which $27.4 \%$ are in African, $7 \%$ in Asia, $6.4 \%$ in Latin America and 1.2\% in North America and Europe (FAO, 2018). Particularly about $22.8 \%$ percent of food insecure people worldwide live in sub-Saharan Africa (SSA) (FAO, 2019). Moreover, out of $31 \%$ food insecure people live in sub Saharan Africa $80 \%$ of them live in rural areas, working as peasants, landless laborers and pastoralists who are often labeled with resource dearth (FAO, 2019).

Worrying about reduction of food insecurity directly or indirectly linked with the household livelihood strategy. Globally extreme poverty has been significantly reduced but in rural area still lags behind (FAO, 2018). For instance, according to FAO (2018) over $29.8 \%$ of the population in Africa, whose live in rural area of the population are food insecure and nearly $70 \%$ of them relies on agriculture for their livelihood. FAO $(2018,2019)$ reports indicate that, where also the largest proportion of the food insecure live in rural area, it is evident that it cannot significantly and sustainably reduce food insecurity without considering their livelihood.

Since sustainable livelihood framework was developed the co-existence of livelihood strategies and livelihood outcome 
(food security in this case) has been a critical discussion for the past two decade. As Seid (2016), still agriculture remains primary means of livelihood to the rural community in Ethiopia, the decline in land holding as well as fragmentation of their holding, the majority of rural household are exposed to food insecurity and chronic poverty. Therefore investigating rural livelihood strategies and food security together would be relevant for rural development polices and strategies.

The major contribution of the existing literature concentration in the determinants on the choice of livelihood strategies (Smith et al, 2000, Tefera et al, 2004, Yishak, 2014, Seid, 2016). On the other hand some of the studies were concerned on food security challenge (Readon et al, 1988. Ramakishna et al, 2002, Fikadu et al, 2010, Hussein, et al, 2013, Hiwot, 2014) and fail to consider household livelihood linkage with food security.

Although few studies tried to link the livelihood strategies and food security have been conducted (Yishak et al, 2014 and Dereje 2016). Yishak et al (2014) used caloric intake/nutritional approach $2200 \mathrm{kcal}$ as a demarcation to food security from food insecurity, but this approach may overlook the variation among household, ability to convert the available resource in to desired resource. And Derje (2016), more interested in identifying the determinants of household livelihood strategies overlook the linkage between household livelihood strategies and food security.

The study on hand add on existing knowledge with particular emphasis on the linkage between household livelihood strategies and food security. Food access based approach measure of food security used in this study as a measure of food security. It contain information about potential and actual income, expenditures, loan and remittance mechanisms as well as trade and market systems provide information about the way food is obtained (Action Center la faim, 2010). Access based measure of food security measurement focus food source, income source and coping strategy. Therefore the main objective of the study is to examine rural livelihood strategies and its effect on food security and specifically the study aim to answer which household livelihood strategy assure foods secure? Which livelihood strategy is more vulnerable to food insecure household?

\section{Material and Methods}

This section presents the source of data, method of data collection and analysis and methodological part through which the objective the study achieved.

\subsection{Source of Data}

This study was used primary data type obtained from self-administered questionnaires'. In addition to primary data, secondary data about the livelihood activities, weather condition, and geographical distribution of the rural household and other related data also collected from district administrative office. Three -stage random sampling procedure was used to select 256 household. The study area was classified into three strata highland, midland and lowland - based on its agro-ecology. Probability proportionate to sample size was employed for the selection of 110 households from the highland stratum, 96 household from midland and 45 households from the lowland stratum. A structured questionnaire was completed by each of 256 households selected.

\subsection{Study Area}

Ethiopia is divided in to nine regional states which are further structured into zone and woreda/districts. The districts are further classified into kebeles (small unit administration). The study is conducted in AngolelanaTera district North showa Zone of the Amhara National Regional State (ANRS) which is located in the Central part of Ethiopia. It is one of the 22 Administrative districts of the North showa administrative zone of the Amhara National Regional State (ANRS). Angolelana Tera district is 28,931 hectare wide, of which $64.5 \%$ and $17.9 \%$ are agricultural land and forest and bush land respectively. The remaining land covered by water (7.2\%) and barren land.

The total population in Anegollana Tera district was about 97,027, of which about 51.37\% of this population was male while the remaining $48.63 \%$ is female. The rural community makes up $86.3 \%$ of the population while the urban population makes up only $13.7 \%$ of the district population. The district is divided into three Agro-ecological zones, namely Dega (highland), Woinadega (medium land), and Kolla (lowland).

Angolelana Tera district situated $120 \mathrm{KM}$ to the north east of Addis Ababa and 20KM away from Debre Birhan town to the south. Anegolelana tera district have 19 rural keble and 3 urban keble. Chacha town is the district administrative town and the second largest market place for the population next to Kotu town. Geographically Angolelana and Tera district surrounded by Hagere Mariam kesem district to the South, Oromia region to the West, Bosona Werena district to the North and Asigeret district to the South east. The temperature is cold and the area receives $800-1500 \mathrm{~mm}$ of rainfall. The altitude of the wereda is around $1700-3400 \mathrm{~m}$. The study area is found between $40^{\circ}-49^{\circ} \mathrm{N}$ and $38^{\circ}-45^{\circ}$ E(Anegollana and tera Destrict administrative office. 2017). 


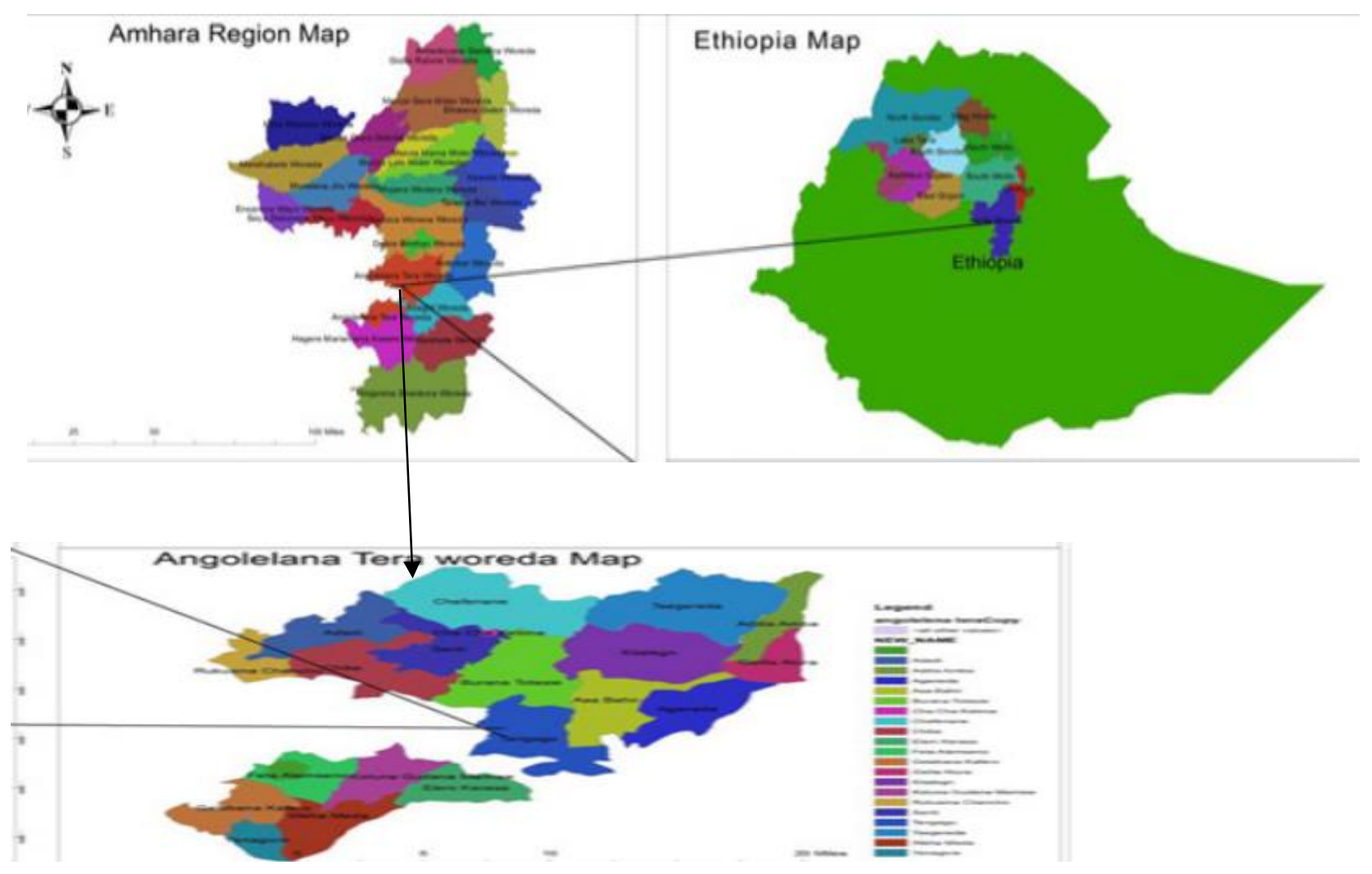

Figure 1. map of the study area

Source: Anegolela Tera district administrative office

\subsection{Analytical Model}

This study was aim to analyze the effect of household livelihood strategies on food security. The household with their own livelihood strategies might become food secure, vulnerable or food insecure. When there is a dependent variable is discrete value with more than two alternatives among on which the decision maker has to choose (i.e. unordered qualitative or polytomous variables), the appropriate econometric model would be either multi-nominal logit or multinomial probit regression model (Greene, 2000). Multi-nomial probit regression model was applied to investigate the linkage among livelihood activities and food security. The rationally for selecting multi-nominal probit model describing as follow;

Regarding estimation, both multi-nominal logit and probit estimate the effect of explanatory variables on dependent variable involving multiple choices with unordered response categories (Greene. 2000). It is a simple extension of the binary choice model and is the most frequently used model for nominal outcomes that are often used when a dependent variable has more than two choices. But in multi-nominal logit model have strong assumption (independent of irrelevant alternative). The normal solution to relax these assumptions is multi-nominal probit regression (Greene, 2000). Therefore the study on hand, a multinomial probit model specification employed.

\subsection{Model Specification}

Following Greene, the multi-nomial probit model for a multiple choice problem is specified as follows:

The structural equation of MNP model are:

$\mathrm{U}_{\mathrm{j}}=\mathrm{X}_{\mathrm{j}}^{\prime} \beta_{\mathrm{i}}+\grave{\varepsilon}_{\mathrm{j}} \quad \mathrm{j}=1, \ldots \ldots \ldots \ldots \mathrm{J}\left[\grave{\mathrm{\varepsilon}}=\grave{\varepsilon}_{1}, \grave{\varepsilon}_{2}, \ldots \ldots \ldots \grave{\varepsilon}_{\mathrm{J}}\right]$

The term in the log-likelihood that correspponds to the choice of alternative $\mathrm{q}$ is

$\operatorname{Prob}[$ choice $q]=\operatorname{prob}\left[\mathrm{U}_{\mathrm{q}}>\mathrm{U}_{\mathrm{j}}, \mathrm{j}=1, \ldots \ldots . \mathrm{J}, \mathrm{j} \neq \mathrm{q}\right]$.

The probability for this occurance is

$\operatorname{Prob}[$ choice $\mathrm{q}]=\operatorname{prob}\left[\grave{\varepsilon}_{1}-\grave{\varepsilon}_{\mathrm{q}}>\left(\mathrm{X}_{\mathrm{q}}-\mathrm{X}_{1}\right)^{\prime} \beta \ldots \ldots \grave{\varepsilon}_{\mathrm{J}}-\grave{\varepsilon}_{\mathrm{q}>}\left(\mathrm{X}_{\mathrm{q}}-\mathrm{X}_{1}\right)^{\prime} \beta\right]$.

The multinomial probit model is similar to multinomial logit model, just like the binary probit model is similar to the binary logit model. The difference is that it uses the standard normal cumulative distribution function, the probability that observation $\mathrm{i}$ will select alternative $\mathrm{j}$ is: 
$\mathrm{p}_{\mathrm{ij}}=\mathrm{p}\left(\mathrm{y}_{\mathrm{i}}=\mathrm{j}\right)=\Phi\left(\mathrm{x}_{\mathrm{ij}}^{\prime} \beta\right)$

The marginal effects $(\delta \mathrm{ij})$ of the characteristics on the probabilities are specified as:

$\delta \mathrm{ij}=\frac{\mathrm{Pij}}{X i}=\mathrm{Pij}=\left(B j-\sum_{j=0}^{j}\left(p_{i j} B_{J}\right)=\mathrm{P}_{\mathrm{ij}}\left(\mathrm{B}_{\mathrm{j}}-\mathrm{B}^{-}\right)\right.$.

Multi-nominal logestic and multi-nominal probit regression helps to identify the role of household livelihood strategy in the food security and show the direction of the likelihood change, but it does not show the magnitude or the level of change. In order to measure the magnitude there are two alternative: applying ordinary least square estimation or computing the marginal effect for both continuous and discrete explanatory variable. Marginal effect can be an informative means for summarizing how change in a response is a related to change in covariate. For categorical variable, the effects of discrete was computed, i.e. the marginal effects for categorical variable show how $\mathrm{P}(\mathrm{Y}=1)$ is predicated to change as $X_{k}$ change from 0 to 1 holding all others $X_{s}$ equal. This can be quite useful, informative and easy to understand. For continuous independent variables, the marginal effect measures the instantaneous rate of change. If the instantaneous rate of change is similar to the change in $\mathrm{P}(\mathrm{Y}=1)$ as $\mathrm{X}_{\mathrm{k}}$ increases by one, this too can be quite useful and intuitive (Greene, 2000). Therefore, the study was compute the marginal effect to measure the magnitude of the change in affecting food security.

\subsection{Variable Description}

Independent variable: the independent variable in this study was the selection of livelihood strategies by farm household i.e. it was identified by categorizing the sample households into livelihood strategy groups based on their choice. Therefore, the polytomous independent variable for multinomial probit was hypothesized to have the following values: $\mathrm{Y}=1$, if the choice lies in farm alone; $\mathrm{Y}=2$, if the choice lies in non-farm alone; $\mathrm{Y}=3$, if the choice lies in farm + nonfarm activities.

On the other hand food security was used as dependent variable and Food security was measured by household food insecurity access scale (HFIAS). In HFIAS, Anxiety and uncertainty about food supply, limited variety of food and insufficient food intake are the main components of the measurement (Coates et al, 2007). The measurement has nine occurrence questions and each question also sub question to identify how it happen i.e. rarely, sometimes and often.

The household grouped in to food secure if the household show no/minimal evidence of food insecurity and the aggregate HFIAS maximum of 10. The household member concern about the adequacy of household food supply and adjustment to $\mathrm{HH}$ food management, including reduced quality of food grouped in mildly food insecure. The household experienced quantity reduction and hunger to some extent by particularly for adult $\mathrm{HH}$ member belongs to moderately food insecure. Finally, if the household reduced the quality of food and experience hunger repeatedly including children grouped in severely food insecure (Coates et al, 2007). Based on the experience each of these components household classified as $(y=1$, if food secure, $y=2$, if food insecure without hunger $y=3$, if moderately food insecure and $y=4$, if severely food insecure) and livelihood strategies was used as an explanatory variable (farming livelihood activity, non-farming livelihood activity and mixed livelihood activity) was used as an explanatory variable.

\section{Results and Discussion}

\subsection{Diagnostic Test}

The appropriateness of the model was tested by using several testing mechanism. First before multi-nominal regression, Varience Inflation Factor (VIF) was conduct to measure the degree of linear relationship among continuous explanatory variable. The mean value of VIF was found 2.37 , which indicate that no problem of multi-collinarity. The model diagnostic was cheek the specification test by making all the coefficients associated with an independent variable are simultaneously equal to zero( $F$ test for over significance) and test the significance of individual variable(t test) the combination of two variable using Wald test. The model goodness of fit can also cheeked by $\mathrm{R}^{2}$, but the study was used the likelihood ratio chi-square test as a measure of goodness of fit. The overall model was statistically significant.

\subsection{Descriptive Statistics}

\subsubsection{Livelihood Strategies}

Rural areas are characterized by the presence of diverse livelihood activities. Some are farm related and other are not farm related (Derje, 2016). This study classified the livelihood strategies in to three major activities. Accordingly, sample household were grouped in to farming activities, non-farming and mixed livelihood (both farm and non-farm) activities based on their activities choice for their livelihood. As observed from the survey result about $60.5 \%$ of the total sample households depend solely on farming activities (crop production and livestock rising). 


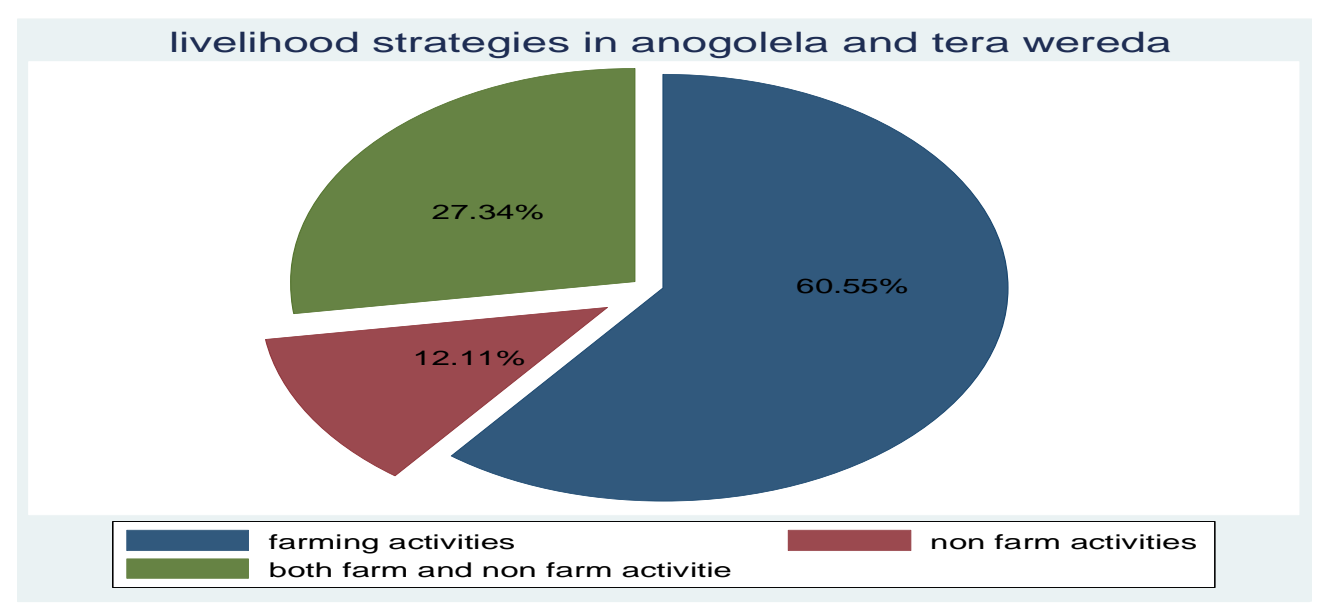

Figure 2. Sample household livelihood strategy cluster in Angolela and Tera district

Source: Survey result, 2019

Even though majority of the household engage in farming activities, about $27.3 \%$ of the household engaged in mixed activities. According to FGD (Focus Group Discussion) the household who engaged in mixed livelihood strategies due to man-made and natural challenge in farming activities. Depending solely on farming livelihood activities facing a challenge such as insects, pest diseases, poor quality of land, land fragmentation and animal diseases forced to combine livelihood activities. Moreover, in addition to farming activities the household who perused the non-farm livelihood activities due to small size of agricultural land, uncertain agriculture and to increase income. The remaining $12.1 \%$ of the sample household perused only non-farm livelihood activities as their livelihood.

\subsection{Household Food Access Security}

Household food security was measured by household food (in) security access scale (HFIAS). The measurements consider anxiety and uncertainty about food supply, limited variety of and insufficient food intake are the main components (Coates et al, 2007). Based on the HFIAS measurement household were classified food secure, mildly food insecure, moderately food insecure and severely food insecure.

In household food security access scale measurement, if the household response for all nine occurrence question "often" the maximum value would be 27 and if the household response to all occurrence question "no" the score would be zero. In this regard, the maximum score obtained from the study was 22 and the minimum score was zero. As Coates et al (2007) suggested that the HFIAS measurement of food security indicate that the higher the score contribute more food insecurity, while the smaller is a representation of lesser food insecurity situation. Higher HFIAS score was recorded in non-farm livelihood activities while, lower HFIAS score was recorded in farming livelihood activities alone and both farm and non-farm livelihood activities. Table below showed that the average (grand) HFIAS was 5.5. The average HFIAS score for each livelihood activities indicates that non-farm activities was 10.4, which is higher than the other activities included in this study. In contrast, lower average HFIAS was recorded in farming activities with the value of 3.74 .

The ANOVA F-Test shows that mean of HFIAS score significantly differ with respect to the three livelihood portfolio at one percent. Hence, livelihood strategies of the respondent were confirmed to affect/support household food security $(\mathrm{p}=0.000)$. The result shows that the household using farming livelihood activities are relatively food secure and the household using non farming activities for their livelihood are more food insecure.

Table 1. Average HFIAS score, one way ANOVA F-test

\begin{tabular}{|c|c|c|c|c|c|}
\hline & \multicolumn{5}{|c|}{ Household livelihood activities } \\
\hline & $\begin{array}{l}\text { Farming } \\
\text { activities }\end{array}$ & Non-farm activities & $\begin{array}{l}\text { Mixed livelihood } \\
\text { act. }\end{array}$ & Grand mean & F-test \\
\hline $\begin{array}{ll}\text { Mean } \\
\text { score }\end{array}$ & 3.74 & 10.4 & 7.2 & 5.5 & $30.9^{* * *}$ \\
\hline
\end{tabular}

*** indicate level of significance at 1 percent.

Source: Survey result, 2019. 


\subsection{Multi-Nominal Probit Estimation on Dimension of the Effect of Livelihood on Food Security}

In the previous section, the chi-square test showed that there is significant association between livelihood and food security at $\mathrm{p}<0.01$. The mean differences in HFIAS score among those livelihood activities were also significant at one percent. In addition, the ANOVA (F-test) for the three livelihood portfolio was conducted and found significant income difference among them at one percent probability level.

The study classified the food security status into four categories (food secure, mildly food insecure, moderately food insecure and severely food insecure). Similarly in HFIAS the standard measure of household food security classified into four categories as food secure, mildly food insecure, moderately food insecure and severely food insecure and the study used this category in multi-nominal probit regression. The dependent variable is the category of household food security status taking a value of 1 if the household were food secure $(n=140), 2$ if the household were mildly food insecure $(n=74), 3$ if the household were moderately food insecure $(n=26)$ and 4 if the household were severely food insecure $(n=16)$. Based on these, multi-nominal probit regression was used to further explain the relationship between livelihood activities and food security situation. In the regression food secure were used as a reference category.

The predicating variable is the livelihood strategy and it has three categories i.e. farming activities, non-farm activities and both farm and non-farm activities. Model result shows that household whose livelihood was farming activities was less likely to be mildly food insecure. Holding other categories constant, the household whose livelihood were of mixed activities the probabilities of mildly food insecure increase by $19 \%$ than those household with farming livelihood activities. Stating differently household drive their livelihood from farming activities were relatively food secure than the household with non-farm activities and mixed activities. The results were significant at less than $1 \%$ probability level. The study confirmed with the expectation and finding of Badulo et al (2008). The result indicate that farming activities better and rewarding activities. The possible reason might be related with the price of food commodity in the market. The higher market price for food commodity, lower the chance of getting adequate food stuff. The household drive their livelihood from non-farm activities has low income and their income unable to cover the food expenditure.

In line with, Badulo et al (2008), Farooq (2014) finding non-farm economy is one of the major sources of livelihood activities for food insecure household. The household whose use farming activities supplement their source of income with the production of cash crop production like lentil, chickpea and vegetable, this helps them to meet their basic needs.

The household whose drive their livelihood confined only non-farm activities are more likely to be severely food insecure. Holding other categories constant, household with only non-farm livelihood activities, the probability of being severely food insecure increase by $29 \%$ than those household who's drive their livelihood from farming livelihood activities. While, in line with Yishak (2014) household who confine their livelihood in to mixed activities were more likely to be severely food insecure than those household with farming activities. Other things remaining constant, the household drive their livelihood from mixed activities the probability of severely food insecure increase by $1.9 \%$ than household with farming livelihood activities. In both case the results were significant at $1 \%$ probability level.

However, household with mixed livelihood activities were relatively better on the level of food security as compared to non-farm livelihood activities. In contrary to prior expectation and Derje (2016) finding Household with farming livelihood activities were more food secures than household in the two livelihood categories. The possible reason could be unprofitable non-farm activities due to lack of support may reduce the role of non-farm activities for maintaining food security. In line with Tefera et al (2004) relatively better off family more focus on intensive farming activities and food insecure household were used non-farm activities for survival. Therefore, farming activities is more rewarding activities to maintain household food security, while the household drive their livelihood from non-farm activities are food insecure. 
Table 2. Parameter estimate on the effects of livelihood activities on food security:Multi Nominal Probit Regression

\begin{tabular}{|c|c|c|c|c|c|}
\hline \multicolumn{2}{|c|}{ Level of household food insecurity } & \multirow{2}{*}{$\begin{array}{l}\text { Coefficient } \\
0.47\end{array}$} & \multirow{2}{*}{$\begin{array}{l}\text { Marginal } \\
\text { effects }\end{array}$} & \multirow{2}{*}{$\begin{array}{l}\text { Std. err. } \\
.419\end{array}$} & \multirow{2}{*}{$\begin{array}{l}\text { Sig. } \\
0.254\end{array}$} \\
\hline Mildly & Non-farm act & & & & \\
\hline Insecure & Mixed act. & 1.13 & 0.19 & 0.26 & $0.000^{* * * *}$ \\
\hline & Constant & -0.89 & & 0.15 & $0.000^{* * * *}$ \\
\hline \multirow{3}{*}{$\begin{array}{l}\text { Moderately } \\
\text { Insecure }\end{array}$} & Non-farm act & 1.79 & 0.22 & 0.42 & $0.000^{* * *}$ \\
\hline & Mixed act. & 1.25 & 0.1 & 0.34 & $0.000^{* * *}$ \\
\hline & Constant & -1.88 & & 0.22 & $0.000^{* * *}$ \\
\hline \multirow{3}{*}{$\begin{array}{l}\text { Severely } \\
\text { Insecure }\end{array}$} & Non-farm act & 2.39 & 0.29 & .46 & $.000^{* * *}$ \\
\hline & Mixed act. & 1.21 & 0.019 & .44 & $0.000^{* * *}$ \\
\hline & Constant & -2.39 & & 0.30 & $0.000^{* * *}$ \\
\hline
\end{tabular}

Base category :food secure and farming activities used as a comparison group Diagnostics

Number of observation $=256$

Prob> chi2 $=0.0000$

$$
\text { LR chi2(6) } \quad=53.76
$$

Log likelihood $=-252.07$

${ }^{* * *}$ indicate significant at $1 \%$ probability level.

Source: survey result, 2019.

\section{Conclusion and Recommendation}

Diversified livelihood activities have been growing importance in the study area. The livelihood activities of the household undertake in the study area were classified in to three broad categories that is farming activities, non-farm activities and both farm and non-farm activities. Even though, non-farm livelihood activities growing importance, majority of the household under take farming livelihood activities.

The study was examined the linkage between household livelihood activities and food security. The household food security was measured based on food access approach, which has linkage with their livelihood activities they undertake. In Household Food Insecurity Access Scale (HFIAS) measurement nine occurrence question was used. The HFIAS results indicate that the higher the score means the higher food insecurity situation and the lower the score the lesser food insecurity situation. Accordingly, average HFIAS was calculated for three livelihoods and found that the household who are using non-farm livelihood activities (10.4) have higher HFIAS score and lower score was recording for the household who are using farming activities (3.74). Household whose depend on farming livelihood activity are more food secure but the household engage non-farm livelihood activity in rural are exposed to food insecurity.

The multi-nominal probit regression result revealed that household who are using farming activities for their livelihood had more likely to be food secure. On the other hand household with non-farm activities alone were observed that more likely to be food insecure. Household with both farm and non-farm activities put in a better position than non-farm activities in their food security though they are uncertain and worry about their food adequacy. In conclusion, undertaking viable livelihood activities is a determining factor for realization of household food security.

Based on the finding, the study indicates the following recommendation:

The food security situation of the household with different livelihood strategies was found to be different. The household with non-farm livelihood activities were found that food insecure. Therefore rural development plan needs proper identification of the household who are using non-farm activities needs intervention and provide better incentive mechanism for maintaining their food security. Comprehensive rural development policy need to designed and implemented in order to keep non-farm household food security status. On the other hand, the household with farming livelihood activities is relatively food secure. Therefore rural development plan needs to provide better access to infrastructure to enhance their production for the household livelihood sustainability.

In conclusion, food security of a household is a reply of available livelihood strategies, which implies household secure their food access based on the activity they undertake. Undertaking viable livelihood strategies is a determining factor for the realization of household food security. Nonetheless, uneven opportunities remain a challenge for rural people. 


\section{Further Studies}

Finally, the study on hand was used subjective food security measurement (HFIAS) for measuring household food security status and found that considerable variation in food access. The study recommended that interested scholar to merge nutritional with subjective proxies to narrow the weakness of subjective household food security measurement.

\section{Reference}

Abdulai, A., \& Anna, C. (2001). Determinants of income diversification amongst rural households in Southern Mali. 437- 452. Food policy 26(2001), 437-452. https://doi.org/10.1016/S0306-9192(01)00013-6

ACF international. (2010). Food Security and Livelihood Assessments: A Practical Guide for Field Workers Technical Department of Food Security and Livelihoods.

Babulo, Bart, M., Fredu, Eric, Jan, N., \& JozeDeckers, E. (2008). Household livelihood strategies and forest dependence in the highlands of Tigray, Northern Ethiopia. Agricultural Systems, 98, 147-155. https://doi.org/10.1016/j.agsy.2008.06.001

Coats, Swndale, \& Bilinsky. (2007). Household food insecurity access scale(HFIAS) for measurement of food access. Indicators guide version 3 USAID Food and Nutrition technical assistance. https://doi.org/10.1037/e576842013-001

Dereje. (2016). Rural Livelihood Strategies and Household Food Security: The Case of Farmers Around Derba Cement Factory, SulultaWoreda, Oromia Regional State. Addis Ababa University, Addis Ababa, Ethiopia.

DFID. (1999). Sustainable livelihoods and poverty elimination by Ashley and Carney. Londen: UK Department for International Development.

FAO. (2019). The state of food security and nutrition in the world, sefegarding against economic slowdown and downturs. Rome: FAO.

FAO, \& ECA. (2018). Regional Overview of Food Security and Nutrition. Addressing the threat from climate variability and extremes for food security and nutrition. Accra.: FAO.

FAO, IFAD, UNICEF, WFP, \& WHO. (2017). The State of Food Security and Nutrition in the World 2017.Building resilience for peace and food security. Rome: FAO.

Farooq. (2014). The rural non-farm economy, livelihood strategies and household welfare in rural Pakistan. Pakistan institute of development economics, Technical papers for 2 nd Asian think tank development forum.

Geremew. (2017). The nexus between livelihood diversification and farm land management strategies in rural Ethiopia. Cogent economics and finance, 5. https://doi.org/10.1080/23322039.2016.1275087

Greene, W. (2000). Econometric analysis. New York, US.: Pearson education LTD.

Hiwot, T. (2014). Determinants of food security in rural farm household in Ethiopia. Master thesis in development studies in Hague University, Netherland.

Hussein, \& Penporn Janekarnkij, P. (2013). Determinants of Rural Household Food Security. Kasetsart J, (Soc. Sci) 34 , 171-180.

Jemal, A., \& Kim, K. (2014). Determinants of household food security in rural Ethiopia: an empirical analysis. Journal of rural development, 37(2).

Mwaniki, A. (2006). Achieving food security: challenge and issue.Discussion paper. Cornel University, US.

Ramakrishna, G., \& Assefa, D. (2002). An Empirical Analysis of Food Insecurity in Ethiopia: The Case of North Wello. Africa Development, Vol. XXVII, Nos. $1 \& 2$.

Reardon, T., Matlon, P., \& Delgado, C. (1998). Coping with Household-level Food Insecurity in Drought-affected Areas of Burkina Faso. World Development, 16(9). https://doi.org/10.1016/0305-750X(88)90109-X

Rural Poverty Report. (2011). New realities, new challenges: new opportunities for tomorrow generation. Rome.

Seid. (2016). Determinants of rural household livelihood strategies:evidence from Weastern Ethiopia. Journal of economics and sustainable development, 7(15).

Smith, D., Gordon, A., Meadows, K., \& Zwick, K. (2001). Livelihood diversification in Uganda: patterns and determinants of change across two rural districts. Food Policy, 26, 421-435. https://doi.org/10.1016/S0306-9192(01)00012-4 
Tefera, Perrets, \& Kirsten. (2004). Diversity in livelihood and farmer strategies in Hararghe highlands, Eastern Ethiopia. International journal of agricultural sustainability, 2(2). https://doi.org/10.1080/14735903.2004.9684573

Yishak, G., Gezahegn, A., Tesfaye, A., \& Dawit, A. (2014). Livelihood Strategies and Food Security of Rural Households in Wolaita Zone, Southern Ethiopia. Developing Country Studies, 4(14).

\section{Copyrights}

Copyright for this article is retained by the author(s), with first publication rights granted to the journal.

This is an open-access article distributed under the terms and conditions of the Creative Commons Attribution license which permits unrestricted use, distribution, and reproduction in any medium, provided the original work is properly cited. 